\title{
Obstetric admissions to the intensive care unit: a five year review
}

\author{
Tapan Pattnaik $^{1}$, Sunita Samal ${ }^{2}$, Sasmita Behuria ${ }^{3}$
}

\begin{abstract}
${ }^{1}$ Department of Obstetrics and Gynaecology, Siksha 'O' Anusandhan University, Bhubaneswar, Odisha, India
${ }^{2}$ Department of Obstetrics and Gynaecology, Mahatma Gandhi Medical College \& Research Institute, Puducherry, India

${ }^{3}$ Department of Obstetrics and Gynaecology, S. C. B Medical College and Hospital, Cuttack, Odisha, India
\end{abstract}

Received: 25 September 2015

Revised: 0329 October 2015

Accepted: 29 October 2015

\section{*Correspondence:}

Dr. Sunita Samal,

E-mail: sunisamal@rediffmail.com

Copyright: ( ) the author(s), publisher and licensee Medip Academy. This is an open-access article distributed under the terms of the Creative Commons Attribution Non-Commercial License, which permits unrestricted non-commercial use, distribution, and reproduction in any medium, provided the original work is properly cited.

\section{ABSTRACT}

Background: Care of the critically ill obstetric patients is a unique challenge particularly because of its unpredictability. The outcome in these patients would not only contribute to the assessment of the quality of patient care but would also enhance the risk stratification of pregnant patients in the evaluation of new therapies. This study is intended to review a series of critically ill obstetric patients admitted to our ICU to assess the spectrum of disease, required interventions, and maternal outcome, and to identify conditions associated with maternal death.

Methods: This retrospective cohort study was conducted in 16-bed medical and surgical ICU in a 500 bedded tertiary care hospital over a period of 5 years (2009-2013) at Bhubaneswar, Odisha, India.

Results: Only 54 obstetric patients were admitted to the ICU which constitutes $2.09 \%$ of all ICU admissions, $0.78 \%$ of emergency obstetric admissions and $0.9 \%$ of the total deliveries. Majority of patients (79.62\%) were admitted during postpartum period. The leading obstetric indication for ICU admission was obstetric hemorrhages (29.6\%). Ectopic pregnancy was common (7 patients) among the obstetric hemorrhages. In the present study maternal mortality was $16.6 \%$, while $70.3 \%$ were improved after treatment. The main cause of maternal death was obstetric haemorrhage (55.5\%). ICU interventions during the stay of the patients in terms of mechanical ventilation were used in $72.2 \%$ of cases. Other interventions included blood \& blood product transfusion in 30 (55.5\%), inotropes in 34 (62.9\%), antihypertensive in $14(25.9 \%)$, anticonvulsant in $16(29.6 \%)$ \& dialysis in 4 (7.4\%) cases.

Conclusions: The need of ICU management for obstetric conditions is on rising trend. The need for ventilatory or inotropic support may predict poor outcome. An adequate adoption of safe motherhood initiative would reduce obstetric ICU admissions and thereby will also reduce the maternal mortality.

Keywords: High risk pregnancy, Obstetric ICU

\section{INTRODUCTION}

Maternal mortality is a basic health care indicator that reflects the health care adequacy of a country. The maternal mortality in India is still 178 per 100000 live births despite different safe motherhood programmes. WHO depicts "there is a story behind every maternal death or life threatening complications". ${ }^{1}$ Major cause of maternal mortality are haemorrhage, sepsis, hypertensive disorder of pregnancy, unsafe abortion, and obstructed labour. So better knowledge of the characteristic, treatment and outcome of these high risk patients will be a step ahead for reduction of maternal mortality and morbidity. Pregnancy and delivery of these high risk cases can involve complications that necessitate admission to critical care units. Critically ill obstetric patients are always a challenge to Intensive Care Unit (ICU) physicians and account for as much as $7 \%$ of the 
ICU admissions in developing countries, while they account for a smaller proportion in developed countries. $^{2,6}$ This study is an attempt to evaluate the incidence, indications, and outcomes of obstetric patients requiring admission to an intensive care unit (ICU) in a tertiary care hospital.

\section{METHODS}

This retrospective cohort study was conducted in 16-bed medical and surgical ICU in a 500 bedded tertiary care hospital, Bhubaneswar, Odisha. The ICU is a closed unit staffed by in-house, full-time, board-certified intensivists. The study population comprised of all obstetric admissions to the ICU at Institute of Medical science and Sum hospital, over a 5-year period (January 2009 to December 2013). We used data collected retrospectively from an ICU database of obstetric patients who were admitted to the ICU. We also collected the following data: baseline demographics, including age, parity, and gestational age. The indication of admission into ICU was noted. The ICU intervention in terms of use of vasopressors and mechanical ventilation (MV) was recorded. The patients were followed up till discharge from the hospital or till death, whichever occurred first. The ICU mortality was the primary outcome. The secondary outcomes were the incidence and indications for obstetric admission to the ICU. Analysis of all the obstetric patients which include antenatal and puerperal cases admitted to ICU in this five year was done. This was compared with total number of ICU admission, total number of deliveries in this tenure. The data were analysed statistically by using percentage.

\section{RESULTS}

Table 1: Demographic Characteristics.

\begin{tabular}{|lll|}
\hline Age & No. of cases & $\%$ \\
\hline$<20$ & 2 & 3.7 \\
\hline $20-30$ & 43 & 79.6 \\
\hline$>30$ & 9 & 16.6 \\
\hline Parity & \\
\hline Primi & 21 & 38.8 \\
\hline Multi & 26 & 48.1 \\
\hline Grand multi & 7 & 12.9 \\
\hline Gestational age at the time of admission & \\
\hline Anepartum & 11 & 20.37 \\
\hline Postpartum & 43 & 79.62 \\
\hline
\end{tabular}

Total number of ICU admission was 2574 and total number of deliveries was 5966 over this 5year period. Only 54 obstetric patients were admitted to the ICU which constitutes $2.09 \%$ of all ICU admissions and $0.9 \%$ of the total deliveries. Among all emergency obstetric admissions (6909) only $0.78 \%$ needed ICU intervention. Most of the patients were 20-30year age group (79.6\%) and multigravida $(61 \%)$ was more as compared to primigravidas $(39 \%)$. Only $20.37 \%$ patients were in antepartum period while majority of patients $(79.62 \%)$ were admitted during postpartum period (Table 1). The main obstetric indications for ICU admission were obstetric haemorrhages $(29.6 \%)$ followed by pregnancyinduced hypertension (25.9\%) and heart disease (16.6\%). Ectopic pregnancy was the leading cause (7 patients) whereas only 4 patients had $\mathrm{PPH}$ among the obstetric haemorrhages (Table 2).

Table 2: Causes of ICU admission.

\begin{tabular}{|lll|}
\hline $\begin{array}{l}\text { Diagnosis } \\
\text { Obstetric } \\
\text { Haemorrhages }\end{array}$ & 16 & $\%$ \\
\hline Ectopic Pregnancy & 7 & $29.6 \%$ \\
\hline PPH & 4 & 12.96 \\
\hline APH & 3 & $7.4 \%$ \\
\hline Ruptured uterus & 2 & 5.5 \\
\hline $\begin{array}{l}\text { Hypertensive } \\
\text { disorder of } \\
\text { pregnancy }\end{array}$ & 14 & 3.7 \\
\hline Heart Disease & 9 & 25.9 \\
\hline Puerperal sepsis & 6 & 16.6 \\
\hline Severe Anaemia & 3 & 11.11 \\
\hline $\begin{array}{l}\text { Post MTP } \\
\text { complication }\end{array}$ & 2 & 5.5 \\
\hline $\begin{array}{l}\text { Hyperemesis } \\
\text { gravidarum }\end{array}$ & 1 & 1.8 \\
\hline $\begin{array}{l}\text { Jaundice in } \\
\text { pregnancy }\end{array}$ & 3 & 1.8 \\
\hline
\end{tabular}

Table 3: Maternal mortality and its cause in ICU.

\begin{tabular}{|lll|}
\hline $\begin{array}{l}\text { Cause } \\
\text { Obstetric } \\
\text { Haemorrhage }\end{array}$ & 5 & $\%$ \\
\hline Sepsis & 2 & 55.5 \\
\hline Medical disorder & 1 & 22.2 \\
\hline PIH & 1 & 11.1 \\
\hline
\end{tabular}

Other indications were puerperal sepsis $(11.11 \%)$, severe anaemia $(5.5 \%)$, post MTP complication $(3.7 \%)$, hyperemesis gravidarum $(1.8 \%)$, and jaundice $(1.1 \%)$. In the present study maternal mortality among the women admitted to ICU was $16.6 \%$. The leading cause of maternal death was obstetric haemorrhage $(55.5 \%)$ followed by sepsis $(22.2 \%)$ (Table 3 ).

Associated medical disorder and pregnancy induced hypertension each constitute $11.1 \%$ for mortality. An ICU intervention during the stay of the patients in terms of mechanical ventilation was used in $72.2 \%$ of cases. Other ICU interventions included blood \& blood product transfusion in $30(55.5 \%)$, inotropes in 34 (62.9\%), antihypertensive in $14(25.9 \%)$, anticonvulsant in $16(29.6 \%)$ \& dialysis in $4(7.4 \%)$ cases. As a surgical procedure suction \& evacuation was done only in two cases (Table4). We had $16.6 \%$ mortality in ICU while 38 patients $(70.3 \%)$ were improved after treatment. A large number 
of patients $(7,12.9 \%)$ had left the hospital against medical advice.

Table 4: ICU intervention.

\begin{tabular}{|lll|}
\hline Procedure & $\begin{array}{l}\text { No. of cases } \\
(\mathbf{n = 5 4})\end{array}$ & $\%$ \\
\hline Mechanical Ventilation & 39 & 72.2 \\
\hline $\begin{array}{l}\text { Blood or blood product } \\
\text { transfusion }\end{array}$ & 30 & 55.5 \\
\hline Ionotrops & 34 & 62.9 \\
\hline Antihypertensive & 14 & 25.9 \\
\hline Anticonvulsant & 16 & 29.6 \\
\hline Dialysis & 4 & 7.4 \\
\hline Surgical intervention & 2 & 3.7 \\
\hline
\end{tabular}

Table 5: Maternal outcome.

\begin{tabular}{|lll|}
\hline Outcome & $\begin{array}{l}\text { No. of Cases } \\
(\mathbf{n = 5 4})\end{array}$ & $\%$ \\
\hline Improved & 38 & 70.3 \\
\hline $\begin{array}{l}\text { LAMA(Left against } \\
\text { medical advice) }\end{array}$ & 7 & 12.9 \\
\hline Death & 9 & 16.6 \\
\hline
\end{tabular}

\section{DISCUSSION}

The majority of maternal deaths occur in the developing countries $(99 \%) .^{2}$ A relatively small number of obstetric patients develop complications that may require ICU admissions. Management of those critically ill patients require multidisciplinary approach. During this 5 year study of obstetric admission to ICU, these patients represented a small proportion of admissions (2.09\%) to our ICU and deliveries $(0.9 \%)$ in the hospital. Only $0.78 \%$ of all obstetric emergency admission required ICU treatment. This is comparable with other studies. American academic of family physicians had mentioned $0.4 \%$ admissions of the total deliveries. ${ }^{3}$ Marbie and Sibai reported that $1 \%$ of women delivered at the University of Tennessee were admitted to Obstetrical ICU. ${ }^{4}$ Only $0.4 \%$ of obstetrical patients needed ICU treatment in a study by Harris \& Foley at the University of California, San Fransico. ${ }^{5}$ Niyaz et al reported obstetric patients accounts for $0.41 \%$ of all ICU admission. ${ }^{6}$ These variations might be due to differences in defining major morbidity criteria for ICU admission \& availability of high dependency unit (HDU), an intermediate care unit. In our study a relatively high obstetric ICU admission might be due to lack of HDU. We had 43 patients $(79.62 \%)$ admitted to ICU who were in postpartum period. In a study by Kipatrick SJ and Matthay MA, 66\% of the women admitted to ICU were post-partum. ${ }^{7}$ This high rate of postpartum admission compare to antepartum may be due to significant hemodynamic changes in postpartum cases. In our study the pre-existing medical conditions which necessitate ICU admission were severe anaemia, heart disease \& jaundice which accounts for $27.7 \%$ only. Majority of admissions were due to obstetric causes. This is similar to the study reported by Vasquez et al in $2007 .^{8}$ Major obstetric haemorrhage which includes PPH, APH, ectopic pregnancy \& ruptured uterus were the most important cause of ICU admission (16, 29.6\%). Hypertensive disorder in pregnancy was the second most cause of ICU admission (14, 25.9\%). This is comparable with studies conducted by Munench et al and Zwart et al which shows haemorrhage \& sepsis was the leading cause of ICU admission. ${ }^{9,10}$ In contrary to this Aldawood showed in his study that pregnancy-induced hypertension (PIH) was the most common obstetric indication for ICU admission followed by obstetric hemorrhage. ${ }^{13}$ This may be due to better management of PIH in the labor wards in our study The maternal mortality was highest with haemorrhage group (55.5\%) as compared to hypertension that was $(11.1 \%)$. Thirty nine critically ill obstetric patients $(72.2 \%)$ required mechanical ventilation during their stay in the ICU whereas only $27 \%$ of ICU obstetric admission required mechanical ventilation in Osinaike et al study ${ }^{11}$. Daniela et al reported as high as $41 \%$ of patients requiring mechanical ventilation. ${ }^{8}$ The most common indications for MV were acute respiratory failure and hemodynamic instability and moreover $11.11 \%$ of the patients in our study had sepsis, and the patients with sepsis were usually more ill and all of them required MV. The maternal mortality among the women admitted to ICU was $16.6 \%$. In a study by Niyaz et al the proportional death rate among obstetric patients in ICU was $33.8 \% .^{6}$ Ghike S, Asegaonkar P reported $31.91 \%$ of maternal mortality rate in obstetric ICU patients ${ }^{12}$. In our study relatively low maternal mortality may be due to increased number of cases who have left hospital against medical advice (LAMA) (12.9\%) and there status could not be followed up. This increase number of LAMA cases is due to high cost of ICU care along with poor socio economic status of the patient.

\section{CONCLUSIONS}

The typical physiological changes of pregnancy, the pharmacokinetics of the drugs administered and the course of the diseases that commonly complicate pregnancy necessitates an essentially high-quality care. These factors must be coupled with the early involvement of a multidisciplinary team consisting of intensivists, obstetricians, and clinical pharmacists, to deliver comprehensive care and to ultimately achieve improved maternal and fetal outcomes. The entire obstetrician team should develop the technical skill for basic HDU management. Above all effective medical care \& early referral system along with availability of tertiary care will reduce the MMR.

\section{Funding: No funding sources \\ Conflict of interest: None declared}

Ethical approval: The study was approved by the Institutional Ethics Committee 


\section{REFERENCES}

1. Making pregnancy safer. WHO Regional office for Europe. Available from: http:// www.euro.who.int/pregnancy. Last accessed on 2008 Sep.

2. Potts M. Can family planning reduce maternal mortality? J Obset Gynaecol East Cent Africa. 1986;5(1-2):29-35.

3. Reason for ICU admission in obstetric patients ICU Tips from other journals 1992, American Academy of family physician. Available from http://www.drplace.com/Reasons for ICU admission in obstetric patients.

4. Marbie WC, Barton JR, Sibal BM. Septic Shock in pregnancy . Obstet Gynaecol. 1997;90:553-61.

5. Harris CM, Foley M. Critical care obstetrics : 13 years of experience in a community practice setting. Obstet Gynaecol. 2002;99;795.

6. Ashraf N, Mishra S, Kundra P, P.veena, Soundaraghavan S, Habeebullah S. Anesthesiology Research and Practice. 2014;2014:1.

7. Kilpatrick SJ, Matthay MA. Obstetric patients requiring critical care: a five year review. Chest. 1992;101(5):1407-12.

8. Vasques DN, Estenssoro E, Canales HS, Reina R, Saenz MG, Das Neves AV, et al. Clinical characteristics and outcomes of obstetric patients requiring ICU admission. Chest. 2007;131:718-24.

9. Munench MV, Baschat AA, Malinow AM, Mighty HE. Analysis of disease in the obstetric ICU at university Referral Centre: A 24 months review of prospective data. J Reprod Med. 2008;53(12):91420.

10. Zwart JJ, Dupvis JR, Richters A. Obstetric ICU admissions, at 2 years nationwide population based cohert study. Intensive Care Med. 2010;36(2):25663.

11. Osinaike B, Amanor - Boadu SD, Sansui AA. Obstetric intensive care: a developing country experience. The Internet Journal of Anesthesiology. 2006;10:2.

12. Ghike S, Asegaonakar P. Why Obstetric patients are admitted to Intesive Care Unit? A Retrospective Study. J South Asian Feder Obst Gynae. 2012;4(2):90-2.

13. Aldawood A. Clinical characteristics and outcomes of critically ill obstetric patients: a ten-year review. Ann Saudi Med. 2011;31(5):518-22.

Cite this article as: Pattnaik T, Samal S, Behuria S. Obstetric admissions to the intensive care unit: a five year review. Int J Reprod Contracept Obstet Gynecol 2015;4:1914-7. 